\title{
Development of Graphite- and Graphene Reinforced Styrene-Butadiene Rubber
}

\author{
Pirityi Dávid Zoltán, ${ }^{1}$ Pölöskei Kornél ${ }^{2}$ \\ Budapest University of Technology and Economics, Faculty of Mechanical Engineering, \\ Department of Polymer Engineering, Budapest, Hungary \\ 1 pirityid@pt.bme.hu \\ 2 poloskei@pt.bme.hu
}

\begin{abstract}
The environmental impact of rubber waste can be reduced by extending the lifetime of rubber products. It can be achieved by developing graphene/rubber nanocomposites with good abrasion resistance. In this paper, we investigated how rubber mixing technologies influence the mechanical properties of rubber. We added various amounts $(0,1,5$ and $10 \mathrm{phr})$ of graphite and graphene to rubber mixtures using a two-roll mill, an internal mixer, a single- and a twin-screw extruder. We performed tensile, tear strength and Shore A hardness tests on the vulcanisates and analysed their fracture surfaces with a scanning electron microscope. Our results show that graphene had a better reinforcing effect than graphite. Rubber mixing via extrusion may contribute to more severe polymer degradation, though their reproducibility is better than that achieved on a two-roll mill or in an internal mixer.
\end{abstract}

Keywords: elastomer, graphite, graphene, nanocomposite.

\section{Introduction}

Increasingly stringent environmental regulations have put the automobile industry under pressure to minimise the ecological footprint of rubber waste. Two approaches are studied in contemporary material science research: a) recycling (i.e. devulcanisation [1, 2]) and b) extending product life cycle [3, 4]. An excellent way to achieve the latter goal is to develop rubber compounds with increased abrasion resistance. Tyre companies are aiming to replace current tire treads with graphene/rubber nanocomposites [5].

Graphene is the most recently found allotrope of carbon: Noveselov and Geim were awarded the Nobel Prize in Physics in 2010 as an acknowledgement of graphene's first-ever isolation. Graphene is a single atomic layer of graphite with extremely high specific surface area (appx. $2400 \mathrm{~m}^{2} / \mathrm{g}$ ). This property allows graphene to form strong adhesive bonds with organic polymers, making it an excellent reinforcement material in polymer composites [6].
Since most rubber products consist of at least ten ingredients, their structure is rather complex. Consequently, their properties must always be studied holistically. It is practically impossible to improve all mechanical properties simultaneously. Results are satisfactory only if an improvement in one property is not accompanied by such deterioration in others that the product's applicability is compromised [5].

In this paper, we compare the applicability of graphite and graphene in rubber compounds as well as investigating the various effects of mixing technologies.

\section{Experimental}

\subsection{Materials}

In this research, we prepared styrene-butadiene rubber (SBR) based compounds to simulate automotive tire treads. The compounds consisted of the following ingredients. 
- SBR: SKS-30 ARKPN SBR 1502, an emulsion type SBR base polymer (producer: Synthez Kauchuk JSC, Voronezh, Russia);

- Carbon black (CB): N330 grade amorphous carbon powder (producer: Kremenchug Carbon Black Plant, Kremenchuk, Ukraine);

- Graphene (GR): xGnP Grade H, graphene nanoplatelets (producer: XG Sciences Inc., Lansing, Minnesota, USA);

- Graphite (G): C-Therm graphite with large specific surface area and an average particle thickness of $1 \mu \mathrm{m}$ (producer: Imerys Graphite \& Carbon, Bodio, Switzerland).

To achieve good curing properties, the following materials were added to the compounds: zinc oxide (ZnO), stearic acid, N-cyclohexyl-benzothiazol-2-sulphenamide (CBS), and tetramethylthiuram disulphide (TMTD). Curing agents were supplied by Tauril Kft.

Table 1. shows the composition of rubber mixtures used for the preliminary experiments in parts per hundred rubber (phr). We first prepared the mixtures on a two-roll mill, then analysed the mixing potential of a single-screw extruder at two screw speeds ( $30 \mathrm{rpm}$ and $120 \mathrm{rpm}$ ). The names of the samples include the screw speed, the mixing technology and the type and amount of the nanostructured particles. These parameters are all shown in subscripts: 'sse' stands for single-screw extruder, 'GR1' means that the mixture contains 1 phr of graphene. Four compounds were prepared: $\mathrm{SBR}_{\text {ee30 }}, \mathrm{SBR}_{\text {ee120 }}$, $\mathrm{SBR}_{\text {ee30_GR1 }}$, $\mathrm{SBR}_{\text {ee120_GR1 }}$.

We based our main experiments on rubber compounds that contained $10 \mathrm{phr}$ of carbon black to achieve better mechanical properties (Table 2.) These compounds were also prepared on a two-roll mill, after which they were subjected to further mixing (either in a twin-screw extruder, or in an internal mixer). The nomenclature of these samples conforms to that of the preliminary experiments. Subscripts following 'SBR' include the following: 'tse', 'im', 'GR' and 'G', meaning twin-screw extruder, internal mixer, graphene, and graphite, respectively. The number at the end of each sample name signifies the amount of particles in phr. The list of samples is as follows: $\mathrm{kSBR}_{\mathrm{ie}}, \mathrm{kSBR}_{\mathrm{ie}_{-} G R 1}, \mathrm{kSBR}_{\mathrm{ie} \_\mathrm{GR} 5}$,

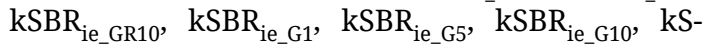
$\mathrm{BR}_{\mathrm{b}}, \mathrm{kSBR}_{\mathrm{b}_{-} \mathrm{GR} 1}, \mathrm{kSBR} \mathrm{b}_{\mathrm{b} G \mathrm{G} 5}, \mathrm{kSBR}_{\mathrm{b} \_\mathrm{GR} 10}, \mathrm{kSBR}_{\mathrm{b}_{-} \mathrm{G} 1}$, $\mathrm{kSBR}_{\mathrm{b}_{-} \mathrm{G} 5}$ and $\mathrm{kSBR}_{\mathrm{b}_{-} \mathrm{G} 10}$.
Table 1. Composition of rubber samples in the preliminary experiments

\begin{tabular}{|c|c|}
\hline Ingredient & phr \\
\hline SBR & 100 \\
\hline GR & $0 ; 1$ \\
\hline ZnO & 5 \\
\hline Stearic acid & 1 \\
\hline CBS & 1 \\
\hline TMDT & 0.8 \\
\hline Sulphur & 2 \\
\hline
\end{tabular}

Table 2. Rubber compositions used for the main experiments

\begin{tabular}{|c|c|}
\hline Ingredient & phr \\
\hline SBR & 100 \\
\hline N330 & 10 \\
\hline GR & $0 ; 1 ; 5 ; 10$ \\
\hline G & $0 ; 1 ; 5 ; 10$ \\
\hline ZnO & 3.3 \\
\hline Stearic acid & 2 \\
\hline CBS & 1.8 \\
\hline TMTD & 1.8 \\
\hline Sulphur & 1.7 \\
\hline
\end{tabular}

Table 3. The settings of the two-roll mill

\begin{tabular}{|l|c|c|c|c|c|}
\hline & \multicolumn{2}{|c|}{$\begin{array}{c}\text { Roll speed } \\
\text { (1/min) }\end{array}$} & \multicolumn{2}{|c|}{$\begin{array}{c}\text { Roll tempera- } \\
\text { ture } \\
\left({ }^{\circ} \mathbf{C}\right)\end{array}$} & $\begin{array}{c}\text { Nip } \\
\text { gap } \\
\text { (mm) }\end{array}$ \\
\hline Roll: & $\mathbf{1 .}$ & $\mathbf{2 .}$ & $\mathbf{1 .}$ & $\mathbf{2 .}$ & \\
\hline 0-5 $\mathrm{min}$ & 3 & 5 & 50 & 70 & 2 \\
\hline 5-10 $\mathrm{min}$ & 5 & 8 & 50 & 70 & 0.75 \\
\hline 10-15 min & 10 & 15 & 50 & 70 & 0.75 \\
\hline
\end{tabular}

\subsection{Technologies}

Each rubber compound was premixed for 15 minutes on a Labtech LRM-SC-110/T3E tworoll mill, according to the parameters presented in Table 3.

After mixing on the two-roll mill, the preliminary rubber compounds were cut into $10-20 \mathrm{~mm}$ wide strips and fed into a Labtech LE 25-30/C single-screw extruder. We were investigating the homogenising effects of extrusion. A temperature ramp was applied over the zones of the extruder. The feed zone was heated to $80^{\circ} \mathrm{C}$ and the temperatures were set gradually higher towards the die, which was heated to $100{ }^{\circ} \mathrm{C}$ to avoid curing in the extruder. 
Similarly to the preliminary experiments, the main experiments also consisted of two mixing steps. After premixing on the two-roll mill, the compounds were either fed to a Labtech LTE 26-44 twin-screw extruder or to a Brabender Plasti-Corder internal mixer. For the twin-screw extrusion, the screw speed was set to $60 \mathrm{rpm}$ and a heat ramp, similar to that used for the single-screw extruder, was applied $\left(80^{\circ} \mathrm{C}\right.$ at the feed zone and $100^{\circ} \mathrm{C}$ at the extruder die). As for the internal mixer, we equipped it with a $50 \mathrm{~cm}^{3}$ mixing chamber and tangential rotors. The mixer's temperature was set to $70{ }^{\circ} \mathrm{C}$ and fill ratio of $70 \%$ was used. Mixing was continued until the melt temperature reached $115^{\circ} \mathrm{C}$.

After mixing, a Collin Pressplate 200E hot press was used to vulcanise the mixtures. 2.7 MPa pressure was applied at $160{ }^{\circ} \mathrm{C}$ for $\mathrm{t}_{90}$ (until $90 \%$ relative curing was reached). We obtained $2 \mathrm{~mm}$ thick rubber sheets, from which we could die cut tensile and tear strength test specimens, using a ball-press.

\subsection{Testing}

Curing properties of the rubber samples were determined on a MonTech D-RPA 3000 rheometer. We ran the experiments in isothermal time sweep mode at $160{ }^{\circ} \mathrm{C}$ with a frequency of $1.67 \mathrm{~Hz}$ and an amplitude of $1^{\circ}$. During testing, an uncured piece of rubber mixture is heated up and a continuous oscillating rotary deformation is applied. The rheometer measures the torque (S') needed to maintain the same strain. An increase in torque corresponds with an increase in modulus, thus the degree of curing can be monitored this way.

We performed the tensile tests on a Zwick Z020 tensile tester according to the ISO 37:2017 standard [7] with a $60 \mathrm{~mm}$ clamping distance and a 500 $\mathrm{mm} / \mathrm{min}$ crosshead speed. The same equipment was used to perform tear strength tests, according to the ISO 34-1:2015 standard [8] $500 \mathrm{~mm} / \mathrm{min}$ crosshead speed and $56 \mathrm{~mm}$ clamping distance. A $1 \mathrm{~mm}$ cut on each tear strength test specimen was made to ensure the tear would originate from the middle of the specimen.

The fracture surfaces of the torn tensile test specimens were analysed on a JEOL JSM 6380LA scanning electron microscope.

We performed Shore A hardness tests, using a Zwick H04.3150 hardness tester, according to the ISO 48-4:2018 standard [9] taking 10 measurements from each sample.

\section{Results}

\subsection{Preliminary experiments}

The tensile and tear strength test results are shown in Tables 4 . and 5. respectively. The reinforcement effect of graphene is apparent from both tests at both screw speeds. However, at the slower setting, 1 phr of graphene increased both the tensile strength and the elongation at break by appx. $60 \%$. The faster screw speed had a generally positive influence on material properties: the tensile parameters of the unfilled compound increased significantly, yet $\mathrm{SBR}_{\text {ee120_GR1 }}$ did not match the tensile properties of $\mathrm{SBR}_{\text {sse30_GR1 }}$. Tear strength results show similar trends: both graphene content and faster screw speed had a positive impact on the tear propagation resistance of the samples.

Based on scanning electron micrographs (Figure 1) we concluded that the particle size of graphene did not change due to the faster screw speed of the single-screw extruder. The difference
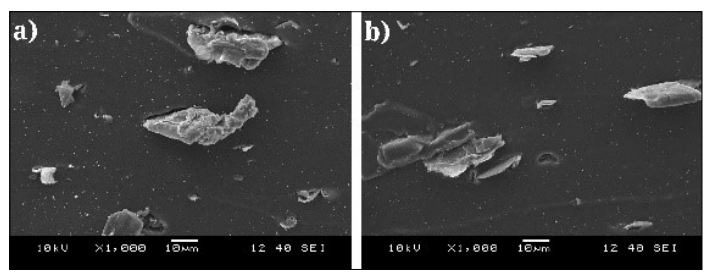

Figure 1. Scanning electron micrographs of the preliminary graphene-containing samples:
a) $S B R_{\text {ee30_GR1 }}$,
b) $S B R_{\text {ee120_GR1 }}$

Table 4. Preliminary tensile test results

\begin{tabular}{|l|c|c|}
\hline \multicolumn{1}{|c|}{ Sample } & $\begin{array}{c}\text { Tensile } \\
\text { strength (MPa) }\end{array}$ & $\begin{array}{c}\text { Elongation at } \\
\text { break (\%) }\end{array}$ \\
\hline $\mathrm{SBR}_{\mathrm{ee} 30}$ & $1.65 \pm 0.05$ & $114.3 \pm 7.0$ \\
\hline $\mathrm{SBR}_{\mathrm{ee} 30 \_G R 1}$ & $2.71 \pm 0.12$ & $181.9 \pm 9.4$ \\
\hline $\mathrm{SBR}_{\mathrm{ee} 120}$ & $2.08 \pm 0.18$ & $164.0 \pm 9.7$ \\
\hline $\mathrm{SBR}_{\mathrm{ee} 120 \_G R 1}$ & $2.30 \pm 0.20$ & $158.4 \pm 16.3$ \\
\hline
\end{tabular}

Table 5. Preliminary tear strength test results

\begin{tabular}{|l|c|}
\hline \multicolumn{1}{|c|}{ Sample } & \multicolumn{1}{c|}{$\begin{array}{c}\text { Tear strength } \\
\text { (N/mm) }\end{array}$} \\
\hline $\mathrm{SBR}_{\mathrm{ee} 30}$ & $4.15 \pm 0.17$ \\
\hline $\mathrm{SBR}_{\mathrm{ee} 30 \_G R 1}$ & $4.29 \pm 0.26$ \\
\hline $\mathrm{SBR}_{\mathrm{ee} 120}$ & $4.40 \pm 0.30$ \\
\hline $\mathrm{SBR}_{\mathrm{ee} 120 \_G R 1}$ & $5.16 \pm 0.38$ \\
\hline
\end{tabular}


in the tested mechanical properties may be due to the distribution of graphene within the matrix as well as the potential degradation of the polymer chains.

\subsection{Comparison of mixing in a twin-screw extruder and in an internal mixer}

After preparing the rubber mixtures, we analysed their curing properties. The vulcanisation curves of the twin-screw extruded samples are shown in Figure 2 and the vulcanisation curves of the samples prepared in the internal mixer are shown in Figure 3. We observed a clear trend in Figure 2: both the minimum and maximum torque values increased with larger additive contents. This phenomenon indicates that the shear modulus of these rubber compounds increased. The presence of the additive particles decreased the optimal vulcanisation time $\left(\mathrm{t}_{90}\right)$ by up to $20 \%$ (in the case of $\mathrm{SBR}_{\text {tse GR10 }}$ ) compared to the unfilled compound.

As shown in Figure 3 the curing properties of the samples prepared in the internal mixer show

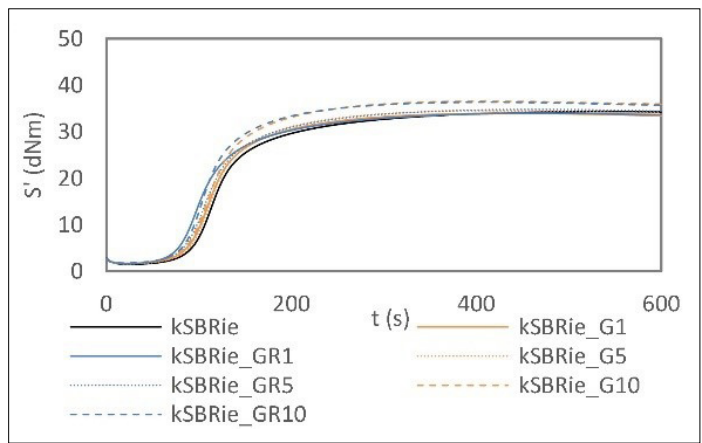

Figure 2. Curing curves of the twin-screw extruded samples

Table 6. Tensile test results for the twin-screw extruded samples

\begin{tabular}{|l|c|c|}
\hline \multicolumn{1}{|c|}{ Sample } & $\begin{array}{c}\text { Tensile strength } \\
\text { (MPa) }\end{array}$ & $\begin{array}{c}\text { Elongation at } \\
\text { break (\%) }\end{array}$ \\
\hline $\mathrm{kSBR}_{\mathrm{ie}}$ & $2.87 \pm 0.08$ & $120.5 \pm 4.1$ \\
\hline $\mathrm{kSBR}_{\text {ie_GR1 }}$ & $3.30 \pm 0.31$ & $128.8 \pm 4.5$ \\
\hline $\mathrm{kSBR}_{\text {ie_GR5 }}$ & $2.75 \pm 0.09$ & $114.7 \pm 1.0$ \\
\hline $\mathrm{kSBR}_{\text {ie_GR10 }}$ & $3.82 \pm 0.30$ & $125.1 \pm 5.8$ \\
\hline $\mathrm{kSBR}_{\text {ie_G1 }}$ & $2.57 \pm 0.17$ & $108.9 \pm 8.2$ \\
\hline $\mathrm{kSBR}_{\text {ie_G5 }}$ & $2.88 \pm 0.16$ & $111.5 \pm 1.8$ \\
\hline $\mathrm{kSBR}_{\text {ie_G10 }}$ & $3.24 \pm 0.19$ & $115.3 \pm 2.1$ \\
\hline
\end{tabular}

a larger variation than those prepared in the twin-screw extruder. The sample containing 10 phr of graphite had a strikingly low maximum torque value. This property normally shows good correlation with the hardness and modulus of rubber compounds. Consequently, we expected $\mathrm{SBR}_{\mathrm{im}_{\mathrm{G}} \mathrm{G10}}$ to have the lowest hardness among this experimental set. In contrast, it was the hardest sample prepared in the internal mixer (Figure 5). The tensile test results for the samples prepared in the twin-screw extruder and the internal mixer are summarized in Tables 6 and 7 respectively.

Our main objective was to identify the differences in the reinforcement capabilities of graphene and graphite at various concentrations. According to Table 6, the use of graphene resulted in better mechanical properties than the use of graphite. The tensile strength of $\mathrm{SBR}_{\mathrm{tse} \text { GR1 }}$ almost matched that of $\mathrm{SBR}_{\mathrm{tse} \text { G10 }}$, meaning that $1 \mathrm{phr}$ of graphene content is equivalent to $10 \mathrm{phr}$ of graphite content. In summary, the best mechanical properties were achieved with a $10 \mathrm{phr}$ graphene content. The tensile strength of SBR $_{\text {tse_GR1 }}$ was $30 \%$ larger than that of the unfilled sample.

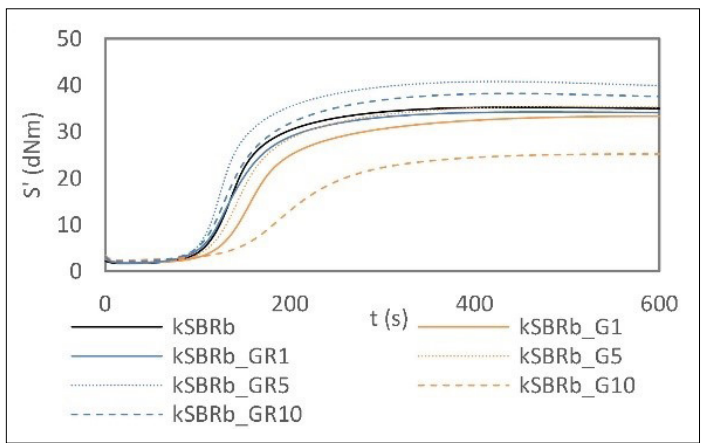

Figure 3. Curing curves of the samples prepared in the internal mixer

Table 7. Tensile test results for the samples prepared in the internal mixer

\begin{tabular}{|l|c|c|}
\hline \multicolumn{1}{|c|}{ Sample } & $\begin{array}{c}\text { Tensile strength } \\
\text { (MPa) }\end{array}$ & $\begin{array}{c}\text { Elongation at } \\
\text { break (\%) }\end{array}$ \\
\hline $\mathrm{kSBR}_{\mathrm{b}}$ & $1.60 \pm 0.03$ & $79.6 \pm 7.2$ \\
\hline $\mathrm{kSBR}_{\mathrm{b} \_\mathrm{GR} 1}$ & $1.27 \pm 0.06$ & $65.3 \pm 10.6$ \\
\hline $\mathrm{kSBR}_{\mathrm{b} \text { GR5 }}$ & $3.05 \pm 0.06$ & $92.6 \pm 4.9$ \\
\hline $\mathrm{kSBR}_{\mathrm{b} \text { GR10 }}$ & $3.96 \pm 0.08$ & $162.5 \pm 18.6$ \\
\hline $\mathrm{kSBR}_{\mathrm{b} \text { G1 }}$ & $1.76 \pm 0.04$ & $93.2 \pm 6.7$ \\
\hline $\mathrm{kSBR}_{\mathrm{b} \_ \text {G5 }}$ & $2.49 \pm 0.07$ & $91.8 \pm 2.0$ \\
\hline $\mathrm{kSBR}_{\mathrm{b} \text { G10 }}$ & $2.54 \pm 0.08$ & $76.4 \pm 1.9$ \\
\hline
\end{tabular}


The tensile properties of the samples prepared in the internal mixer (Table 7) were considerably poorer than those of the extruded samples. Only one of the samples surpassed $100 \%$ relative elongation: $\mathrm{SBR}_{\mathrm{im} \_\mathrm{GR} 10}$. This single sample outperformed all other samples, including the extruded compounds. This dual behaviour may be explained by two factors: a) the low repeatability of mixing in the internal mixer, and b) the potential polymer degradation in the twin-screw extruder (causing the lower maximum values).

The tear strength of all experimental samples versus their respective additive content is plotted in Figure 4. Samples that had been prepared in the internal mixer outperformed those prepared in the extruder significantly. $\mathrm{SBR}_{\mathrm{im} \_\mathrm{GR} 10}$ showed outstanding tear strength in comparison with all other samples. This phenomenon further supports that better properties are attainable in the internal mixer, due to the polymer degradation during extrusion.

The Shore A hardness of the samples is shown in Figure 5. It is evident that increasing additive content resulted in higher Shore A hardness, regardless of the type of mixing and type of nanostructured additive. There was a single outlier, $\mathrm{SBR}_{\mathrm{tse}}$, its hardness surpassed that of the samples with 5 phr nanostructured additive content.

We analysed the morphology of the composites via scanning electron microscopy. The most revealing micrographs are presented in Figure 6. We selected the images to represent the fracture surface as closely as possible. The layered structure of both graphene and graphite is clearly visible, but graphite had a higher number of distinguishable layers. Graphene particles seem to have stayed intact, protruding out of the fracture surface. In contrast, graphite layers seem to have undergone some deformation, creating more irregularities in the system. Samples that had been prepared via extrusion contained thin fibrils that made the adhesion between the nanostructured additive particles and the rubber matrix stronger. The distribution of the additive particles appears to be better in the extruded samples.

\section{Conclusions}

During our preliminary experiments, we showed that graphene can significantly improve the mechanical properties of rubber compounds even at small ( 1 phr) concentration.

The main experiments revealed that better distribution of the nanostructured additive particles

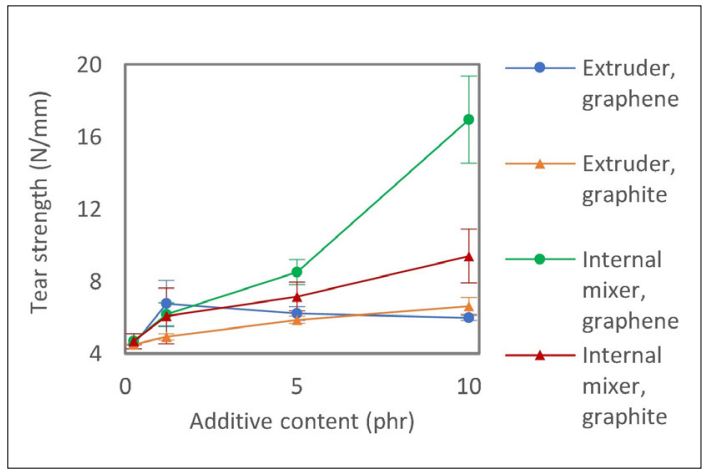

Figure 4. Tear strength of the rubber composites vs. their additive content.

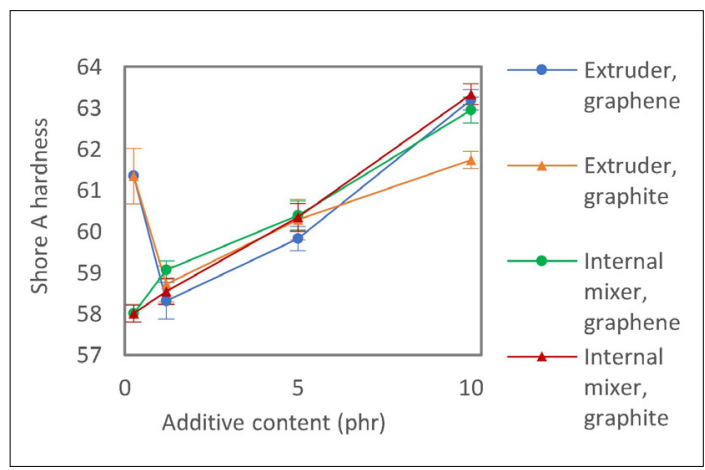

Figure 5. Shore A hardness of the prepared rubber composites vs. their additive content.
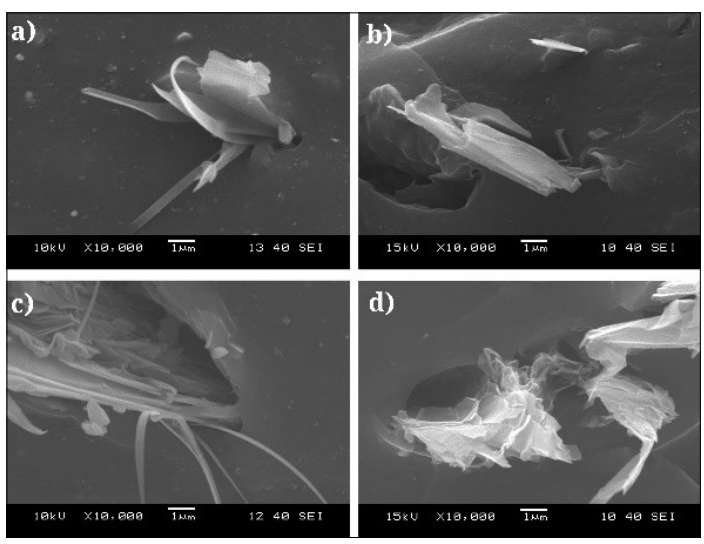

Figure 6. Scanning electron micrographs of the fracture surfaces of tensile test specimens:
a) $\left.\left.k S B R_{i e_{-} G R 10}, b\right) k S B R_{b_{-} G R 10}, c\right) k S B R_{i e_{-} G 10}$
d) $k S B R_{b_{-} G 10}$

is attainable via twin-screw extrusion, compared to preparation in an internal mixer. Despite this, the compounds prepared in the internal mixer outperformed the extruded samples in terms of 
hardness and tear strength. A possible explanation is that extrusion might have caused some polymer degradation due to more intense shearing.

Altogether, the future development of graphene-reinforced rubber compounds has great potential. The effects of mixing technologies should be studied more deeply to reach clear conclusions.

\section{Acknowledgement}

The research reported in this paper and carried out at BME has been supported by the National Research, Development and Innovation Office, Hungary (2017-2.3.6-TÉT-CN-2018-00002). Hereby, we would like to thank Szilvia Móritz for her help with the execution of the experimental work.

\section{References}

[1] Formela K., Hejna A., Zedler Ł., Colom X., Cañavate J.: Microwave treatment in waste rubber recycling - recent advances and limitations. Express Polymer Letters, 13. (2019) 565-588.

https://doi.org/10.3144/expresspolymlett.2019.48

[2] Kaewpetch B., Prasongsuk S., Poompradub S.: Devulcanization of natural rubber vulcanizates by Bacillus cereus TISTR 2651. Express Polymer Letters, 13. (2019) 877-888.

https://doi.org/10.3144/expresspolymlett.2019.76

[3] Cao L., Sinha T. K., Tao L., Li H., Zong C., Kim J. K.: Synergistic reinforcement of silanized silica-graphene oxide hybrid in natural rubber for tire-tread fabrication: A latex based facile approach. Composites Part B: Engineering, 161. (2019) 667-676.

https://doi.org/10.1016/j.compositesb.2019.01.024

[4] Hajba S., Tábi T.: Cross effect of natural rubber and annealing on the properties of poly(lactic acid). Periodica Polytechnica Mechanical Engineering, 63. (2019) 270-277.

https://doi.org/10.3311/PPme.12825

[5] Guo H., Ji P., Halász I. Z., Pirityi D. Z., Bárány T., Xu Z., Zheng L., Zhang L., Liu L., Wen S.: Enhanced fatigue and durability properties of natural rubber composites reinforced with carbon nanotubes and graphene oxide. Materials, 13. (2020) 5746. https://doi.org/10.3390/ma13245746

[6] Berki P., László K., Tung N. T., Karger-Kocsis J.: Natural rubber/graphene oxide nanocomposites via melt and latex compounding: Comparison at very low graphene oxide content. Journal of Reinforced Plastics and Composites, 36. (2017) 808-817.

https://doi.org/10.1177/0731684417690929

[7] ISO 37:2017: Rubber, vulcanized or thermoplastic -Determination of tensile stress-strain properties, 2017.

[8] ISO 34-1:2015: Rubber, vulcanized or thermoplastic - Determination of tear strength - Part 1: Trouser, angle and crescent test pieces, 2015.

[9] ISO 48-4:2018: Rubber, vulcanized or thermoplastic - Determination of hardness - Part 4: Indentation hardness by durometer method (Shore hardness), 2018. 